\title{
INSTITUTO IBEROAMERICANO DE LA HAYA PARA LA PAZ, LOS DERECHOS HUMANOS Y LA JUSTICIA INTERNACIONAL (IHH)
}

\author{
HÉCtor Olásolo* \\ Universidad de UTRECht, Holanda \\ hectorolasolo@gmail.com
}

Muchas gracias a los organizadores de este II Congreso de Derechos Humanos de Estudiantes de la Universidad de Chile por invitarme a estar presente en este magnífico escenario.

Como primer ponente quiero comenzar analizando la realidad de la Corte Penal Internacional, para más adelante referirme a sus principales desafíos.

El Estatuto de Roma se aprobó el 17 de julio de 1998, y entró en vigor el 1 de julio de 2002. La Fiscalía se constituyó al año siguiente, en el año 2003. En ese mismo año fueron elegidos los magistrados de la Corte, estableciéndose así la estructura judicial de la Corte, de manera que esta pudo comenzar a operar. Desde entonces han pasado siete ańos. En estos años se abrieron varias investigaciones. En junio de 2004 se abrió la investigación en la situación en la República Democrática del Congo, después en el norte de Uganda, posteriormente en la República Centroafricana, luego en Darfur (Sudán), y el 31 de marzo de 2010 se ha autorizó la apertura de la investigación en Kenia. Existen, por tanto, en la actualidad, cinco investigaciones abiertas con respecto a otras tantas situaciones.

Se utiliza el término "situación" porque la Corte Penal Internacional no puede conocer de investigaciones sobre "casos", es decir, no puede abrir investigaciones con respecto a individuos concretos por una serie de incidentes específicos, sino que debe abrir investigaciones con respecto de situaciones definidas por parámetros personales, territoriales, y eventualmente personales. Por ejemplo, la situación en la República Democrática del Congo, a partir del 1 de julio de 2002. Iniciada la investigación de una situación, se procede a investigar a los principales actores en el conflicto, y en el marco de esa investigación aparecerán indicios racionales de criminalidad con respecto a alguno(s) de los dirigentes de dichos grupos, lo que dará lugar a que la Fiscalía solicite una orden de arresto.

\footnotetext{
* Catedrático de Derecho Penal y Procesal Internacional, Universidad de Utrecht; Presidente del Instituto Iberoamericano de La Haya para la Paz, los Derechos Humanos y la Justicia Internacional; Director de la Clínica Jurídica sobre Conflicto Armado, Derechos Humanos y Justicia Internacional, Universidad de Utrecht.
} 
Por lo tanto, no cabe, como se ha escuchado con relativa frecuencia en el pasado, iniciar una investigación contra Hugo Chávez, o llevar a la Corte Penal Internacional a Álvaro Uribe, puesto que no se inician las investigaciones con respecto a personas concretas, sino en relación a situaciones en su conjunto. De esta manera, si se quiere llevar la situación de Colombia ante la Corte, la tendremos que llevar definida de una manera objetiva, como la situación de violencia que se ha producido en el conjunto del territorio de dicho Estado, o en una región del mismo, a partir del primero de noviembre de 2002 (fecha de entrada en vigor del Estatuto de Roma para Colombia), o de una fecha posterior elegida conforme a criterios objetivos.

Las cinco investigaciones arriba mencionadas tienen por objeto situaciones relativas a países que se encuentran en la zona de África central, puesto que Uganda hace frontera con la República Democrática del Congo, al norte de la República Democrática del Congo se encuentra Sudán, que también limita con Uganda, a la izquierda se encuentra la República Centroafricana, y finalmente Kenia se encuentra también en esa misma región.

Ahora bien, es importante subrayar que existen además una serie de exámenes preliminares sobre situaciones que no pertenecen al área geográfica al que pertenecen las cinco investigaciones en curso, como son las relativas a las situaciones de Colombia, Georgia, Costa de Marfil, o incluso al conflicto entre Palestina e Israel ${ }^{1}$. Mi intervención se va a centrar precisamente en esta fase procesal, la fase de examen preliminar, que es aquella en la que se decide si se comienza a investigar una determinada situación, porque en la misma se cumplen los requisitos exigidos por el Estatuto de Roma para que la Corte inicie una investigación con respecto a una determinada situación.

Antes de entrar en la sustancia de mi intervención, me gustaría explicar brevemente las razones por las que he decidido centrar la misma en la fase de examen preliminar. En Colombia, el Estatuto de Roma entra en vigor el 1 de noviembre del año 2002. A partir de ese momento se producen una serie de negociaciones que terminan con la aprobación de la Ley de Justicia y Paz en el año 2005. En el año 2006 se dicta la sentencia C-370 del Tribunal Constitucional que declara la inexequibilidad de una buena parte de sus disposiciones -aquí tenemos en esta mesa redonda a uno de los padres de dicha sentencia-, y a partir de entonces, comienzan toda una serie de actuaciones que, si bien todavía no han llevado más que a un puñado de sentencias, han generado ya ciertas decisiones de carácter emblemático o simbólico.

Por ejemplo, hace apenas dos meses se dictó la decisión en el caso del desplazamiento forzoso del corregimiento de Mampuján en la zona de los Montes de María (entre los departamentos de Sucre y Bolívar). ¿Qué dictaminó la Sala de Conocimiento de Justicia y Paz en esta decisión? En esta decisión de primera instancia, que es actualmente objeto de apelación, la Sala de Conocimiento

1 Estamos en este momento a la espera de que la Corte se pronuncie sobre si tiene jurisdicción en relación con el mismo sobre la base de la presunta capacidad jurídica internacional de Palestina, que según esta última podría otorgar a la Corte jurisdicción según el Estatuto de Roma. Se trata este de un dictamen que está preparándose en este momento en la Fiscalía de la Corte. 
contextualizó los hechos declarados como probados, refiriéndose por primera vez al fenómeno de los delitos de lesa humanidad, así como a la existencia de prácticas consistentes en violaciones graves del derecho internacional humanitario (crímenes de guerra).

A través de esta decisión, la Sala de Conocimiento estableció asimismo un sistema comprensivo de reparación que incluye modalidades de reparación individual y colectiva. Dentro de las modalidades de reparación individual, la Sala de Conocimiento acogió como referente los estándares establecidos por la Corte Interamericana de Derechos Humanos. En consecuencia, dejando a un lado las reglas tradicionales de prueba en el proceso civil en materia de daños, adoptó la equidad como criterio central para la valoración del daño, y siguió los estándares de indemnización individual recogidos en los casos de las matanzas de Pueblo Bello e Ituango del año 2006 por la Corte Interamericana. Asimismo, la Sala de Conocimiento estableció un sistema de reparación colectiva tendente a reconstruir la infraestructura del lugar afectado, crear una casa de cultura, campos de deporte y a restablecer las infraestructuras viales.

En tercer lugar, la decisión de la Sala de Conocimiento en el caso Mampuján, puso un énfasis particular en la necesidad de reforzar la persecución de los bienes de los postulados desmovilizados (es decir, de los antiguos miembros de los grupos de autodefensa y paramilitares que se desmovilizaron en el ańo 2005). Para ello, ordenó la creación de una unidad específica en la Fiscalía para la identificación de estos bienes, y estableció un procedimiento para la extinción de su dominio en el que la carga de la prueba ya no está en quién pretende extinguir el dominio, sino en quién pretende que dicho dominio no se extinga. Asimismo, ordenó la vinculación al fondo de reparación de todos aquellos bienes lícitos e ilícitos de las personas que hayan sido condenadas por la Sala de Casación Penal de la Corte Suprema por parapolítica.

La relevancia de esta última medida es aparente si se tiene en cuenta que, a raíz del proceso de Justicia y Paz, y de las confesiones de quienes se han desmovilizado, se han adelantado decenas de investigaciones y enjuiciamientos contra parlamentarios, gobernadores y otros cargos de la administración pública colombiana, que han generado varias condenas por concierto para delinquir debido a la pertenencia a un grupo paramilitar o de autodefensas. En virtud de que la Corte Constitucional había declarado la responsabilidad solidaria de todos los miembros pertenecientes a un mismo grupo paramilitar o de autodefensas, la Sala de Conocimiento vinculó al proceso de Justicia y Paz todos los bienes de las personas condenadas por sentencia firme dictada por la Sala de Casación Penal de la Corte Suprema, y ordenó su inmediata realización e integración en el fondo de reparación.

Todo esto hubiera sido impensable en Colombia si no hubiese existido la Corte Penal Internacional, porque a pesar de que Colombia haya excluido a través del artículo 124 del Estatuto de Roma la jurisdicción de la Corte sobre crímenes de guerra hasta noviembre de 2009, esto no significa que haya excluido también su jurisdicción por crímenes de lesa humanidad y genocidio. De ahí que con la entrada en vigor del Estatuto de Roma para Colombia, el 1 de noviembre de 2002, surge una nueva instancia de control jurisdiccional supranacional que monitorea lo que se desarrolla a nivel nacional, y que abre un examen preliminar para ejercer cierta presión sobre las autoridades nacionales. 
En este sentido, es importante señalar que un examen preliminar no es una investigación. Por el contrario, un examen preliminar es una fase procesal previa de carácter jurisdiccional, en la que se analiza si corresponde activar la jurisdicción latente de la Corte sobre una determinada situación de crisis. De esta manera, se puede afirmar que la Corte no está conociendo de la situación colombiana, sino que la está examinando preliminarmente desde hace seis años.

Pero este sistema de monitoreo de la autoridades nacionales, visitas al país e informes, ¿qué efectos está teniendo? Por lo pronto, se pueden observar una serie de actuaciones de carácter judicial, así como un conjunto de resoluciones en materia de verdad y reparación que, si bien tiene un componente limitado en relación con el componente justicia, eran absolutamente impensables hace apenas seis u ocho años. De hecho, hoy en día existen cientos de casos abiertos contra miembros de las Fuerzas Armadas o de la Fuerza Pública como consecuencia de esas confesiones, y se está investigando a una tercera parte de los parlamentarios del Congreso de 2006. Esto, sin la actuación de la Corte Penal Internacional, no hubiese sido posible. Y la Corte Penal Internacional ha podido favorecer este fenómeno a través de su examen preliminar, manteniendo la presión sobre el Estado, y sin necesidad de recurrir a la apertura de una investigación de carácter penal.

Pero ¿qué ocurre cuando hablamos de una investigación de carácter penal? Porque este es el problema fundamental que se plantea. Con ello, llego a la cuestión central de mi exposición, que no es otra sino hasta qué punto se puede incentivar a las jurisdicciones nacionales a actuar manteniendo la presión sobre las mismas. En otras palabras, ¿̨hasta qué punto la Corte Penal Internacional puede prevenir situaciones que todavía no se han consumado mediante su intervención en el momento de desarrollarse ciertos actos preparatorios como la instigación o al iniciarse la fase de ejecución (tentativa)? Esta intervención se produciría, en su caso, mediante la apertura de un examen preliminar antes de que se comiencen a producir fenómenos de las dimensiones del genocidio en Ruanda, el cual se produjo después de años de preparación, y una vez que hasta cincuenta y una emisoras de radio y medios de comunicación escrita hubieran contribuido durante tres ańos a crear la llamada "prensa del odio".

A este respecto, conviene recordar que desde el año 1991 y hasta 1994, cincuenta y tres publicaciones y medios de comunicación fueron catalogados dentro de esa categoría de prensa y radio del odio en Ruanda. La pregunta es, por tanto, si la Corte Penal Internacional, a través de exponer al mundo que se está llevando a cabo un proceso de esta naturaleza que conlleva un riesgo serio de originar el desencadenamiento de una ola de violencia masiva, se encuentra en posición de desarrollar a través de su examen preliminar una intervención oportuna que permita prevenir eficazmente el inicio de este tipo de olas de violencia.

Es importante recordar en este sentido que la Corte abre un examen preliminar con una mera decisión del fiscal. No es por tanto necesario el acuerdo de un grupo de Estados como en el caso del Consejo de Seguridad de las Naciones Unidas, cuyas resoluciones se ven además sometidas al veto de sus cinco miembros permanentes. En el caso de la Corte, es suficiente con una resolución del fiscal. Por ello, la Corte posee una función importante en materia de prevención que, sin embargo, todavía no ha desarrollado, debido a su reciente puesta en marcha. Será una vez que se consolide como insti- 
tución en el sistema de relaciones internacionales, cuando podrá comenzar a ejercitar con mayores garantías esa función de prevención, de la que depende en gran medida el éxito de su actuación, puesto que si fracasa le quedará únicamente la función de poner fin a la impunidad mediante la investigación y enjuiciamiento de aquellos delitos internacionales ya cometidos.

El principal problema que enfrenta la Corte en la investigación y enjuiciamiento de los delitos sometidos a su jurisdicción es la dificultad para llevar a cabo las investigaciones, preparar los casos, y enjuiciar en La Haya hechos ocurridos en Bangui, en Kinshasa, en Kampala, en Nairobi... La razón es muy simple, puesto que cuando uno va a Bangui por primera vez, uno no sabe por dónde se mueve; a no ser que contrate personal del lugar, difícilmente uno va a conocer las diferentes comunas, difícilmente podrá uno conocer los diferentes pueblos que han estado involucrados en situaciones de conflicto como la que tuvo lugar en Ituri, donde hasta 17 milicias estaban operando simultáneamente en una zona en la que convivían tan solo cuatro millones de habitantes.

Uno tiene que ser conocedor del área y ser consciente de que cuando ha habido una violencia tal que ha generado cientos de miles de víctimas, el tejido social se destruye en gran medida, y la polarización es tal que los distintos grupos de la sociedad civil que consigue permanecer cohesionados mantienen, de una manera u otra, importantes intereses en el actuar de la Corte. Pero al mismo tiempo, la propia Corte, para poder operar no puede sino confiar en intermediarios: los funcionarios de la Corte tienen que confiar necesariamente en intermediarios para poder encontrar a las víctimas, así como por razones de protección, puesto que no pueden acercarse a aquellas, ya que una conversación entre una víctima y un funcionario de la Corte puede suponer que aquella termine siendo amenazada o asesinada por su posible cooperación con la Corte.

Asímismo, también es muy difícil poder evaluar a priori cuál es el carácter, la naturaleza, las intenciones, o la agenda de los intermediarios. En otras palabras, ¿qué es lo que el intermediario ha podido decir a aquella persona que se le presenta como víctima antes de que se le tome declaración o posteriormente en el período que va desde la toma de declaración a la víctima hasta el momento en que declara en el juicio oral.

Y esta es precisamente una de las realidades de la Corte, porque en el primer juicio oral de Justicia y Paz ante la Corte (el juicio contra Thomas Lubanga), se encuentra suspendido. Pero ¿por qué se encuentra suspendido? Se encuentra suspendido porque en ese juicio oral lo que se ha hecho por más de un ańo es imputar el reclutamiento de nińos; de nińos hema (menores de 15 ańos), pero es que el imputado era el líder del grupo hema, con lo cual el imputado tiene en ocasiones mejor acceso a los propios testigos de la Fiscalía que la propia Fiscalía. Y entonces, ¿qué es lo que alegó la defensa? La defensa alegó que, al acercarse al entorno de algunos de los testigos de la Fiscalía, se encontraba con que al parecer ciertos intermediarios de la Fiscalía podrían haber podido predeterminar el testimonio de los testigos en una cierta dirección. La Sala reaccionó ante esto pidiendo el nombre de uno de esos intermediarios, para ver de quién se trataba, y estudiar qué es lo que podía haber dicho a los testigos. La Fiscalía, sin embargo, decidió por razones de protección del testigo no revelar dicho nombre, lo que provocó la suspensión del proceso. 
La suspensión del proceso es algo incidental, puesto que la cuestión central viene determinada por las dificultades para poder llevar a cabo una investigación en un Estado en el que no existen infraestructuras porque ha habido una situación de violencia colectiva, sobre todo cuando se opera principalmente desde el exterior del territorio afectado, y que por ende se tiene una capacidad limitada para poder discernir cuáles son los intereses en juego que puedan encontrarse involucrados.

Teniendo en cuenta los obstáculos para llevar a cabo su función de investigación y enjuiciamiento, es necesario potenciar la función de prevención de la Corte, de manera que la primera solo se ejercite con respecto a los "máximos responsables" en aquellas situaciones en las que la función de prevención no haya podido desarrollarse de manera efectiva. Pero ¿de quién estamos hablando cuando nos referimos a "máximos responsables"? De Omar al-Bashir; de Jean Pierre Bemba. Ese tipo de individuos, personas que están al máximo nivel y que pueden verse como responsables últimos de situaciones de violencia colectiva donde la prevención no ha funcionado.

Finalmente, y con esto voy a terminar, quiero abordar una cuestión en materia de víctimas. Se dice que una de las piedras angulares del Estatuto de Roma de la Corte Penal Internacional es el reconocimiento a las víctimas del derecho de acceso a la propia Corte mediante la presentación de comunicaciones al fiscal, y su posterior personación en las actuaciones. Pero la realidad es que la Corte ha sido hasta el momento ciertamente "timorata" a la hora de permitir una participación sistemática y significativa de las víctimas. ¿Por qué? Porque las víctimas rompen el "embudo". Hasta ahora, si se observa con detenimiento, toda comunicación de las víctimas tiene que ir dirigida al fiscal de la Corte, quien a su vez decide sobre la apertura de una investigación, aunque a veces necesite la autorización de la Sala de Cuestiones Preliminares ${ }^{2}$. Si la determinación de los cargos y de los hechos objeto del proceso también dependen de la Fiscalía, esta última se convierte en una especie de "embudo de la Comunidad Internacional”: ipor ahí pasa todo!, y es ahí donde "ha de aplicarse la presión" a los efectos de determinar en cierta medida qué situaciones llegan a ser objeto de investigación, y qué casos surgen como consecuencia de las mismas. Ahora bien, si damos a las víctimas una función sustantiva mediante la posibilidad de presentar ante las Sala de Cuestiones Preliminares pretensiones autónomas relativas a la apertura y definición de las situaciones objeto de investigación y de los casos objeto de audiencias de confirmación de cargos, este "embudo" se resquebrajaría.

La participación de las víctimas en las actuaciones ante la Corte es fundamental, y con un ejemplo voy a terminar esta presentación. En la primera audiencia de confirmación de cargos que se celebró ante la Corte (caso Thomas Lubanga Dyilo), la Fiscalía caracterizó el conflicto que se produjo en el segundo semestre de 2002 y en el año 2003 en Ituri entre los grupos hema (representado por el movimiento político UPC y su brazo armado FPLC) y lendu (representado por la milicia FNI) como un conflicto de carácter interno entre dos grupos étnicos que en un rincón escondido de África se llevaban enfrentando durante varios años.

2 Artículo 53 (1) y 15(3) del Estatuto de Roma. 
Los representantes legales de las víctimas se opusieron a esta caracterización del conflicto armado al alegar que del análisis de los elementos de prueba presentada por la Fiscalía y la defensa en dicha confirmación de cargos, y sin necesidad de traer elementos de prueba adicionales al proceso, se podía concluir la existencia de una intervención continuada de las Fuerzas Armadas del pueblo de Uganda en dicho conflicto Así, para los representantes legales de las víctimas, las distintas milicias que operaron en Ituri (distrito del noreste de la República Democrática del Congo, que constituía el teatro de operaciones) se formaron en Kampala, capital de Uganda, de manera que cuando una de ellas dejaba de servir los intereses del gobierno de Uganda, se generaba una nueva. Asimismo, las fuerzas ugandesas tuvieron presencia en el territorio del distrito de Ituri, y lucharon conjuntamente con las diferentes milicias, hasta el punto de que quien tomaba el control de la capital del distrito (Bunia) y de otras ciudades importantes, eran aquellas que se encontraban apoyadas por las Fuerzas Armadas ugandesas. En consecuencia, según los representantes legales de las víctimas, no se trataba este de un conflicto armado de carácter interno, sino de un conflicto armado de carácter internacional, posición que fue, en gran medida, acogida por la Sala de Cuestiones Preliminares en su decisión de confirmación de cargos de 29 de enero de 2007.

De esta manera, se puede afirmar que fue la voz de los representantes legales de las víctimas la que, en gran medida, hizo que la Sala se replanteara la recaracterización del conflicto armado. En este sentido, la importancia de este hecho no puede ser pasada por alto en cuanto que, nos guste o no, la decisión que la Corte Penal Internacional vaya a adoptar sobre la naturaleza de un conflicto armado va a tener indiscutiblemente un impacto sobre la manera en que el mismo va a quedar caracterizado en un futuro. De ahí, la importancia de atribuir a las víctimas una participación sustantiva en las actuaciones ante la Corte, en las que se dilucida dicha naturaleza. 